\title{
Article \\ Cardiovascular Function and Exercise Capacity in Childhood Cancer Survivors
}

\author{
Barbara Reiner ${ }^{1, *(\mathbb{C})}$, Irene Schmid ${ }^{2}$, Thorsten Schulz ${ }^{1}$, Jan Müller ${ }^{1,3} \mathbb{D}^{-}$, Alfred Hager ${ }^{3}$, Julia Hock ${ }^{3}(\mathbb{D}$, \\ Peter Ewert $^{3}{ }^{\mathbb{D}}$, Cordula Wolf ${ }^{3}$, Renate Oberhoffer-Fritz ${ }^{1,3,+} \mathbb{D}$ and Jochen Weil ${ }^{3,+}$ \\ 1 Institute of Preventive Pediatrics, Technical University Munich, 80992 Munich, Germany; \\ thorsten.schulz@tum.de (T.S.); j.mueller@tum.de (J.M.); renate.oberhoffer@tum.de (R.O.-F.) \\ 2 Division of Pediatric Hematology and Oncology, Department of Pediatrics, \\ Dr. von Hauner Children's Hospital, University Hospital Munich, LMU Munich, 80337 Munich, Germany; \\ Irene.Schmid@med.uni-muenchen.de \\ 3 Department of Pediatric Cardiology and Congenital Heart Disease, German Heart Center Munich, \\ Technical University Munich, 80636 Munich, Germany; hager@dhm.mhn.de (A.H.); hock@dhm.mhn.de (J.H.); \\ ewert@dhm.mhn.de (P.E.); wolf@dhm.mhn.de (C.W.); weil@dhm.mhn.de (J.W.) \\ * Correspondence: barbara.reiner@tum.de; Tel.: +49-89-289-24900 \\ + These authors contributed equally to this work.
}

check for updates

Citation: Reiner, B.; Schmid, I.;

Schulz, T.; Müller, J.; Hager, A.; Hock,

J.; Ewert, P.; Wolf, C.;

Oberhoffer-Fritz, R.; Weil, J.

Cardiovascular Function and

Exercise Capacity in Childhood

Cancer Survivors. J. Clin. Med. 2022,

11, 628. https://doi.org/10.3390/

jcm11030628

Academic Editor: Anastasios

Kollias

Received: 1 December 2021

Accepted: 19 January 2022

Published: 26 January 2022

Publisher's Note: MDPI stays neutral with regard to jurisdictional claims in published maps and institutional affiliations.

Copyright: () 2022 by the authors. Licensee MDPI, Basel, Switzerland. This article is an open access article distributed under the terms and conditions of the Creative Commons Attribution (CC BY) license (https:// creativecommons.org/licenses/by/ $4.0 /)$.

\begin{abstract}
Introduction: Childhood cancer survivors (CCS) might be at high risk of additional chronic diseases due to cardiotoxic side effects. The aim of this study was to analyze long-term side effects of cancer therapy on vascular structure/function, cardiac biomarkers and on physical activity. Methods: In total, 68 asymptomatic patients aged 16-30 years with childhood cancer (diagnosed $10.6 \pm 3.9$ years ago) were examined from 2015-2020. (Central) blood pressure and pulse wave velocity were registered via the oscillometric method, while carotid intima-media thickness (cIMT) was measured non-invasively by ultrasound. cIMT values of patients were compared to healthy controls ( $n=68$; aged $22.3 \pm 3.5$ years). Patients' exercise capacity was recorded. The plasma N-terminal pro-brain natriuretic protein (NTproBNP) and troponin levels were measured as cardiac biomarkers. CCS were categorized in groups with low, moderate and high anthracyclines. Results: No differences were found in cIMT between patients and controls as well as between patients with various anthracycline dosage. Patients with high dose anthracyclines showed a significant lower performance versus patients with moderate dose anthracyclines $\left(84.4 \%\right.$ of predicted $\mathrm{VO}_{2}$ peak; $\left.p=0.017\right)$. A total of $11.6 \%$ of CCS had abnormal NTproBNP values which correlated with received anthracycline dosage $(p=0.024 ; \mathrm{r}=0.343)$. Conclusion: NTproBNP levels and exercise capacity might be early markers for cardiovascular dysfunction in CCS and should be included in a follow-up protocol, while cIMT and troponin seem not to be adequate parameters.
\end{abstract}

Keywords: childhood cancer survivors; long-term side effects; cardiovascular dysfunction; anthracyclines; carotid intima-media thickness

\section{Introduction}

In Germany, around 2183 persons aged below 18 years develop cancer every year. The survival rate has increased to about $82 \%$, which is why long-term effects of illnesses and therapies are becoming more and more important [1].

Childhood cancer survivors (CCS) are known for the increased prevalence of cardiovascular diseases as adults [2,3]. Even 5 years after the diagnosis, the consequences of the original cancer and subsequent treatment may influence the likelihood of death [3]. Nowadays, cardiovascular disease is the leading cause of non-cancer mortality in CSS [4].

The predisposition of CCS for additional risk factors such as obesity, hypertension, dyslipidemia, glucose intolerance and metabolic syndrome [5] are, next to the side effects of cancer therapy [6], good reasons for a long-term, preventive approach in follow-up. 
For follow-up treatment of (asymptomatic) survivors and to reduce the burden of longterm side effects of diagnosis and therapy, an early detection of cardiovascular diseases is necessary.

To prevent cardiovascular events in later life, it is very important to identify predictors by which the individual risk of cardiotoxicity and cardiovascular events can be estimated. So far, the main focus has been on echocardiographic values (e.g., speckle tracking, tissue doppler imaging) in order to identify subclinical cardiac dysfunctions [7]. In this article, however, the focus is on vascular parameters.

Some studies have already found differences in vascular function and structure in CCS soon after therapy compared to controls [8]. Despite the observed abnormalities, the influence of isolated and combined factors (anthracycline dose, volume of radiation, traditional risk factors) are not well known [9]. Since there is also an increased risk that traditional risk factors for cardiovascular events are present in CCS, e.g., due to an inactive lifestyle, the likelihood of early vascular impairments, such as subclinical atherosclerosis and arterial stiffness, increases further $[8,10]$.

In general, the atherosclerotic process begins early in life with an accumulation of fatty streaks [11,12]. A measurement of carotid intima-media thickness (cIMT) can reveal early changes of the arterial wall structure. The measurement of cIMT is non-invasive, has already been used many times in children and helped to detect high-risk groups with abnormal vascular wall thickness $[8,13]$. Therefore, it is a good surrogate marker to detect apparently healthy people with increased cardiovascular risk [14].

$\mathrm{N}$-terminal pro-brain natriuretic peptide (NTproBNP) and cardiac troponin are serum biomarkers that can be useful to evaluate cardiotoxicity after cancer therapy [15]. While cardiac troponin (cTnT) is a protein and biomarker of myocardial damage, NTproBNP are natriuretic peptides and might help to detect cardiac stress [15] and early left ventricular dysfunction.

CCS meet the recommended level of physical activity less often than healthy peers do $[16,17]$. Further, several studies showed that the level of physical activity and fitness is impaired in CCS [18]. Knowing that physical activity is beneficial for well-being and health $[18,19]$, as well as its protective effect on mortality [20], it is very important to evaluate and encourage physical activity. A cardio-pulmonary exercise test (CPET) is one of the best objective methods for determining exercise capacity [21].

The aim of this study was to investigate long-term side effects of cancer therapy in young people. Of special interest were early signs of atherosclerosis in these patients, so we measured cIMT, as a surrogate marker. Further, the blood pressure, pulse wave velocity (PWV), laboratory profile/cardiac biomarkers and exercise capacity of CCS were evaluated.

\section{Materials and Methods}

\subsection{Study Subjects}

In 2015, our institutions started a collaboration for an oncologic cardiologic surveillance service with a fixed clinical protocol for CCS (Supplement File S1). For the current analysis, medical charts were reviewed from all CCS that were examined at the pediatric cardiology outpatient unit at the German Heart Center Munich between March 2015 and September 2020. Finally, 68 patients aged $16-30$ years (21.0 \pm 3.0 years) with a measurement of the carotid intima-media thickness were enrolled in this retrospective study. Age, sex, height, weight, body-mass-index (BMI) as well as details of cancer diagnosis and therapy were abstracted from medical records (Tables 1 and 2). The patients belonged to the following diagnostic groups: Acute Lymphoblastic Leukemia, ALL $(n=23)$, ALL relapse + stem cell transplantation $(n=8)$, Hodgkin's Lymphoma $(n=17)$, Sarcoma $(n=15)$, Others $(n=6)$. On average, they were diagnosed aged $10.4 \pm 4.8$ years. The average time since their diagnosis was $10.6 \pm 3.9$ years (min. 3.8 years; max. 19.6 years). 
Table 1. Patients' characteristics and details to anthracyclines and carotid intima-media thickness (cIMT).

\begin{tabular}{|c|c|c|c|c|c|c|c|}
\hline & $\mathbf{N}$ & Sex & $\begin{array}{c}\text { Age } \\
\text { (years) }\end{array}$ & $\begin{array}{l}\text { Height } \\
\text { (cm) }\end{array}$ & $\begin{array}{l}\text { Weight } \\
\text { (kg) }\end{array}$ & BMI & $\begin{array}{l}\text { cIMT } \\
(\mathrm{mm})\end{array}$ \\
\hline & & female $n(\%)$ & $($ Mean \pm SD) & $($ Mean \pm SD) & $($ Mean \pm SD) & $($ Mean \pm SD) & $($ Mean \pm SD $)$ \\
\hline CCS total & 68 & $35(51.5)$ & $21.0 \pm 3.1$ & $170.2 \pm 10.0$ & $67.5 \pm 15.8$ & $23.1 \pm 4.1$ & $0.457 \pm 0.033$ \\
\hline $\begin{array}{l}\text { CCS with high } \\
\text { anthracyclines }\end{array}$ & 37 & $21(56.8)$ & $20.6 \pm 2.5$ & $168.6 \pm 11.2$ & $62.1 \pm 12.9 * 1$ & $21.7 \pm 3.0 * 2$ & $0.454 \pm 0.032$ \\
\hline $\begin{array}{l}\text { CCS with moderate } \\
\text { anthracyclines }\end{array}$ & 27 & $12(44.4)$ & $21.5 \pm 3.8$ & $172.2 \pm 7.7$ & $73.6 \pm 17.7 * 1$ & $24.7 \pm 4.7 * 2$ & $0.461 \pm 0.037$ \\
\hline $\begin{array}{l}\text { CCS with none/low } \\
\text { anthracyclines }\end{array}$ & 4 & $2(50.0)$ & $21.1 \pm 2.5$ & $171.0 \pm 12.9$ & $74.3 \pm 9.7$ & $25.6 \pm 4.0$ & $0.468 \pm 0.015$ \\
\hline $\begin{array}{l}\text { CCS subgroup with } \\
\text { all data }\end{array}$ & 43 & $20(46.5)$ & $21.2 \pm 3.2$ & $170.8 \pm 9.8$ & $68.6 \pm 17.6$ & $23.3 \pm 4.4$ & $0.459 \pm 0.037$ \\
\hline Healthy controls & 68 & $35(51.5 \%)$ & $22.3 \pm 3.5$ & $174.3 \pm 9.3$ & $69.0 \pm 11.3$ & $22.6 \pm 2.6$ & $0.465 \pm 0.039$ \\
\hline
\end{tabular}

Body-mass-index $=$ BMI; numbers $=n$, standard deviation $=\mathrm{SD}$, childhood cancer survivors $=$ CCS; Anthracycline dose $\left(\mathrm{mg} / \mathrm{m}^{2}\right)$ : low < 100; moderate $=100-250$; high $>250$; comparison of patients with moderate and high dose of anthracycline ${ }^{*} 1 p=0.012 ;{ }^{*} 2 p=0.003$.

Table 2. Data of all childhood cancer survivors with cardiopulmonary exercise test and all other data of patients with low, moderate and high anthracyclines.

\begin{tabular}{|c|c|c|c|c|c|}
\hline & Total & $\begin{array}{c}\text { Low/None } \\
\text { Anthracyclines }\end{array}$ & $\begin{array}{c}\text { Moderate } \\
\text { Anthracyclines }\end{array}$ & $\begin{array}{c}\text { High } \\
\text { Anthracyclines }\end{array}$ & $\begin{array}{c}p \text {-Value Moderate } \\
\text { vs. High } \\
\text { Anthracyclines * }\end{array}$ \\
\hline & 43 & $n=2$ & $n=20$ & $n=21$ & \\
\hline $\begin{array}{c}\text { Systolic Blood } \\
\text { Pressure }(\mathrm{mmHg})\end{array}$ & $118.6 \pm 11.6$ & $122.5 \pm 9.2$ & $120.2 \pm 11.0$ & $116.7 \pm 12.4$ & 0.368 \\
\hline $\begin{array}{c}\text { Diastolic Blood } \\
\text { pressure }(\mathrm{mmHg})\end{array}$ & $70.0 \pm 8.3$ & $69.0 \pm 14.1$ & $71.0 \pm 9.5$ & $69.1 \pm 6.9$ & 0.522 \\
\hline $\begin{array}{l}\text { Central systolic } \\
\text { blood pressure } \\
(\mathrm{mmHg})\end{array}$ & $108.8 \pm 11.7$ & $113.5 \pm 9.2$ & $110.0 \pm 13.5$ & $107.2 \pm 10.3$ & 0.685 \\
\hline PWV & $5.0 \pm 0.5$ & $5.2 \pm 0.6$ & $5.1 \pm 0.6$ & $4.9 \pm 0.5$ & 0.348 \\
\hline NTproBNP & $67.7 \pm 62.8$ & $31.5 \pm 12.0$ & $42.7 \pm 42.5$ & $94.9 \pm 70.9$ & $0.005 * *$ \\
\hline $\begin{array}{l}\text { Troponin }(\mathrm{ng} / \mathrm{mL}) \\
\% \text { of predicted }\end{array}$ & $0.005 \pm 0.002$ & $0.006 \pm 0.003$ & $0.005 \pm 0.002$ & $0.005 \pm 0.002$ & 0.979 \\
\hline $\begin{array}{c}\mathrm{VO}_{2 \text { peak }}(n=16 \text { vs. } \\
n=17)\end{array}$ & $90.7 \pm 21.2$ & $81.0 \pm 29.7$ & $99.4 \pm 25.0$ & $83.3 \pm 12.7$ & $0.011 * *$ \\
\hline cIMT (mm) & $0.459 \pm 0.037$ & $0.479 \pm 0.014$ & $0.460 \pm 0.039$ & $0.457 \pm 0.037$ & 0.639 \\
\hline
\end{tabular}

For subgroup comparisons, the patients were classified based on the received anthracycline dose12: (1) less than $100 \mathrm{mg} / \mathrm{m}^{2}$; (2) $100-250 \mathrm{mg} / \mathrm{m}^{2}$; (3) more than $250 \mathrm{mg} / \mathrm{m}^{2}$.

Because cIMT norm values are not transferrable [22], we recruited our own control group ( $n=68 ; 22.3 \pm 3.5$ years) from the same setting (parts of these data are already published elsewhere $[13,23])$. Therefore, we used the same material, standardized ultrasound protocol and same sonographers.

For detailed analyses, only patients with data in all additional required parameters were included. Overall, 43 patients were able to perform a cardiopulmonary exercise test and had registered values for age, height, weight, BMI, age at diagnosis, time off therapy, anthracyclines and radiation exposures as well as values for blood pressure (peripheral and central), PWV and laboratory (total cholesterol, low density lipoprotein (LDL) cholesterol, high-density lipoprotein (HDL) cholesterol, amino-terminal pro-brain natriuretic peptide = NTproBNP, high sensitivity troponin $\mathrm{T}=\mathrm{cTnT}$ ). 
All patients, controls and their guardians (for children under 18 years of age) gave written consent for anonymous publication of their data. The need for an ethical board evaluation was waived due to the complete retrospective design of the study.

\subsection{Clinical Protocol}

cIMT was measured strictly in accordance with the guidelines of the "Cardiovascular Prevention Working Groups of the Association for European Pediatric Cardiology" [24]. For all cIMT measurements, a semiautomated ultrasound system, the Cardiohealth Station of Panasonic (Yokohama, Japan), was used. The central frequency of the linear-array transducer was $8.9 \mathrm{MHz}$. In brief, the guidelines state that all patients should be placed in a supine position with their head tilted $45^{\circ}$ and the neck slightly stretched. All measurements were performed on the far wall of the common carotid artery and approximately $1 \mathrm{~cm}$ distal to the bulb at the end-diastolic phase. In order to obtain meaningful values, the cIMT was measured at four angles $\left(120^{\circ}, 150^{\circ}, 210^{\circ}\right.$ and $\left.240^{\circ}\right)$ using B-Mode ultrasound. A mean value was calculated from these values for further analyses. Systolic and diastolic blood pressure as well as central blood pressure and PWV were measured after 5 min of rest in a supine position using the oscillometric Mobil-O-Graph®(IEM Healthcare, Stolber, Germany).

Total cholesterol and its subtypes, LDL cholesterol and HDL cholesterol, were analyzed by enzymatic assays and photometric detection on the Cobas C501 analyzer (Roche Diagnostics, Mannheim, Germany). Troponin (cTnT) and NT-proBNP were quantified by electrochemiluminescence immunoassay (ECLIA) methods on the Cobas E411 analyzer (Roche Diagnostics). All analyses were performed as part of routine patient diagnostics in a highly quality-controlled manner in accordance with the guidelines of the German Medical Association (Rili-BaeK) at the Institute of Laboratory Medicine of the German Heart Center. A level of $<0.01 \mathrm{ng} / \mathrm{mL}$ was defined as normal for cTnT. For NTproBNP we used sex-specific norm values. While values $>170 \mathrm{ng} / \mathrm{L}$ are conspicuous for women, values > $100 \mathrm{ng} / \mathrm{L}$ are considered abnormal for men.

Exercise capacity was determined on an electronically braked bicycle ergometer (Corival, Lode, Groningen, NL) in an upright position by a symptom-limited cardio-pulmonary exercise test (CPET) with a ramp-wise protocol and breath-by-breath metabolic analysis (Encore, Vyaire Medical, INC, Mettawa, IL, US). The standardized protocol, following the guidelines of the American College of Cardiology and American Heart Association [25], is routine in our institute and often described [26]. All patients who completed their cardiopulmonary exercise test with exhaustion (respiratory exchange ratio $>1.1$ ) were included in further evaluations. For an assessment of the performance, the peak oxygen uptake $\left(\mathrm{VO}_{2}\right.$ peak) of each patient is given as a percentage of the individually expected norm $\left[\left(\mathrm{VO}_{2}\right.\right.$ peak $(\%$ norm $\left.)\right]$. Values $<80 \%$ of predicted norm $[27,28]$ were considered as "abnormal".

\subsection{Data Analyses}

Continuous variables are presented as mean \pm standard deviations, while categorical variables (such as sex) are reported as counts and percentages. For group comparisons, either t-test, Mann-Whitney U Test or Kruskal-Wallis tests for unpaired samples were carried out, depending on the number of groups, sample size and type of distribution. Multiple linear regression analyses adjusted for covariates were used to assess the mean differences in cIMT and values of blood pressure as well as PWV between various groups. Age, sex, height and weight were entered as covariates.

The association of treatment-related parameters and biomarkers were analyzed using Spearman's rank correlation. Where necessary, the calculations were adjusted for covariates (sex, age, height and weight) in a multiple linear regression model.

For statistical analyses SPSS 23.0 software was used (BMI Corp., Armonk, NY, USA). Two-sided $p$-values $<0.05$ were considered statistically significant. 


\section{Results}

Patients' characteristics are shown in Table 1. All of them were in NYHA class I and asymptomatic at the time of follow-up. The mean age at cancer diagnosis was $10.4 \pm 4.8$ years, and an average of $10.6 \pm 3.9$ years have passed since then. In our cohort, 64 patients $(94.1 \%)$ had chemotherapy and 22 of them also received radiotherapy. The mean cumulative anthracycline dose was $261.99 \pm 108.76 \mathrm{mg} / \mathrm{m}^{2}$.

In a comparison of cIMT between patients and healthy subjects, no differences were detected after adjustment for sex, age, height and weight $(p=0.528)$. Further, there was neither a difference in cIMT between patients with moderate and high anthracyclines $(p=0.415)$ nor between patients with and without radiotherapy $(p=0.412)$ after adjustment for the same covariates. cIMT did not correlate with age at diagnosis $(p=0.688)$ nor with the time duration between diagnosis and follow up $(p=0.423)$. In addition, the patients with different cancer types did not differ in cIMT $(p=0.813)$.

The patient subgroups (moderate, high anthracycline dose) did not differ in age and height, but weight $(p=0.012)$ and BMI $(p=0.003)$. There were no differences in peripheral or central blood pressure, PWV or any other laboratory parameter between the two groups with moderate and high anthracycline dosage (Table 2).

There was no difference in cIMT between patients with normal and abnormal NTproBNP ( $p=0.983$ ) after adjustment for sex, age, height and weight differences. Further, no correlation of cIMT values to blood pressure or laboratory parameters were detected.

Only $85.4 \%$ of the patients were able to perform a CPET until exhaustion (respiratory exchange ratio (RER) > 1.1). Out of them, $28.6 \%$ of the patients had less than $80 \%$ of the predicted $\mathrm{VO}_{2}$ peak. Patients with high anthracyclines performed less than patients with moderate anthracyclines $\left(84.4 \pm 10.5\right.$ vs. $99.6 \pm 24.4 \%$ of predicted $\mathrm{VO}_{2}$ peak.; $p<0.017$ ) (Figure 1a,b). A previous radiation treatment showed no additional effect on the performance.

Association of exercise capacity andreceived

anthracyclines dosage inchildhood cancer survivors

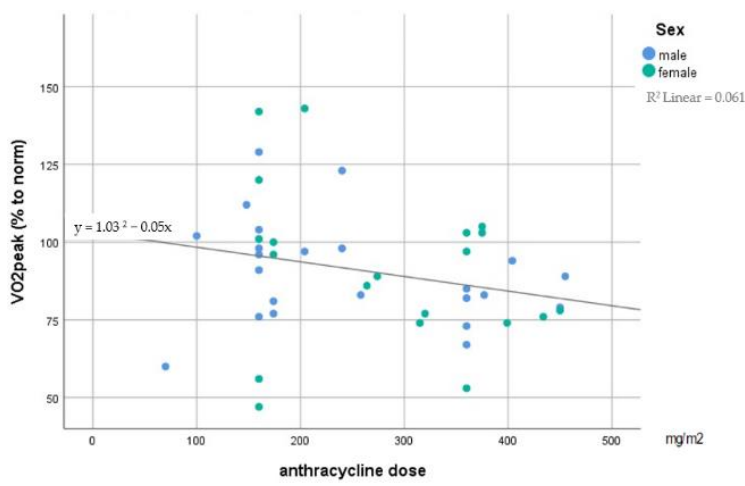

(a)
Exercise Capacity of childhood cancer survivors that received moderate or high dosage anthracyclines

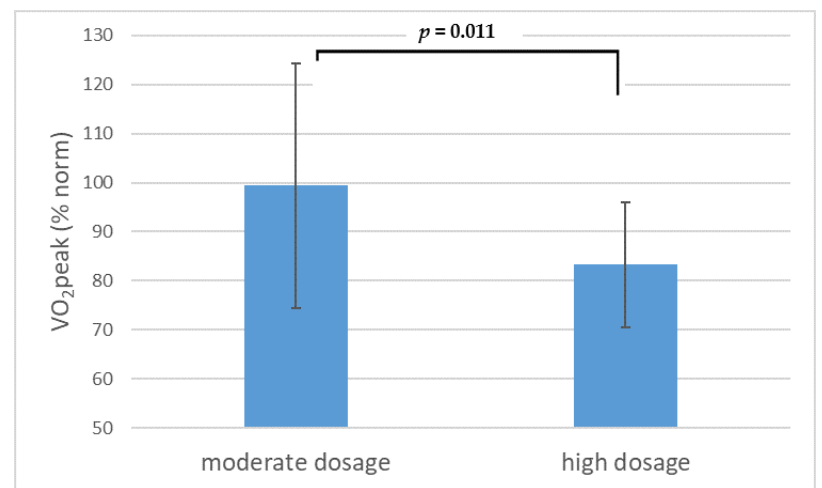

(b)

Figure 1. (a) Correlation of exercise capacity and anthracycline dosage in childhood cancer survivors about 10 years after cancer diagnosis; $\mathrm{VO}_{2}$ peak (\%to norm) = \%predicted peak oxygen uptake; (b) Correlation of exercise capacity and anthracycline dosage in childhood cancer survivors about 10 years after cancer diagnosis. Anthracycline dosage $\left(\mathrm{mg} / \mathrm{m}^{2}\right)$ : moderate = 100-250; high > 250; $\mathrm{VO}_{2}$ peak $(\%$ to norm $)=\%$ predicted peak oxygen uptake.

NTproBNP was abnormal in $11.6 \%$ of the patients. A total of $32.6 \%$ (14 of 43 patients) had NTproBNP values above $100 \mathrm{ng} / \mathrm{L}$. NTproBNP is positively associated with anthracyclines exposure $(r=0.343 ; p=0.024)$ (Figure 2$)$. 
Association of NtproBNP and received anthracycline dosage in childhood cancer survivors

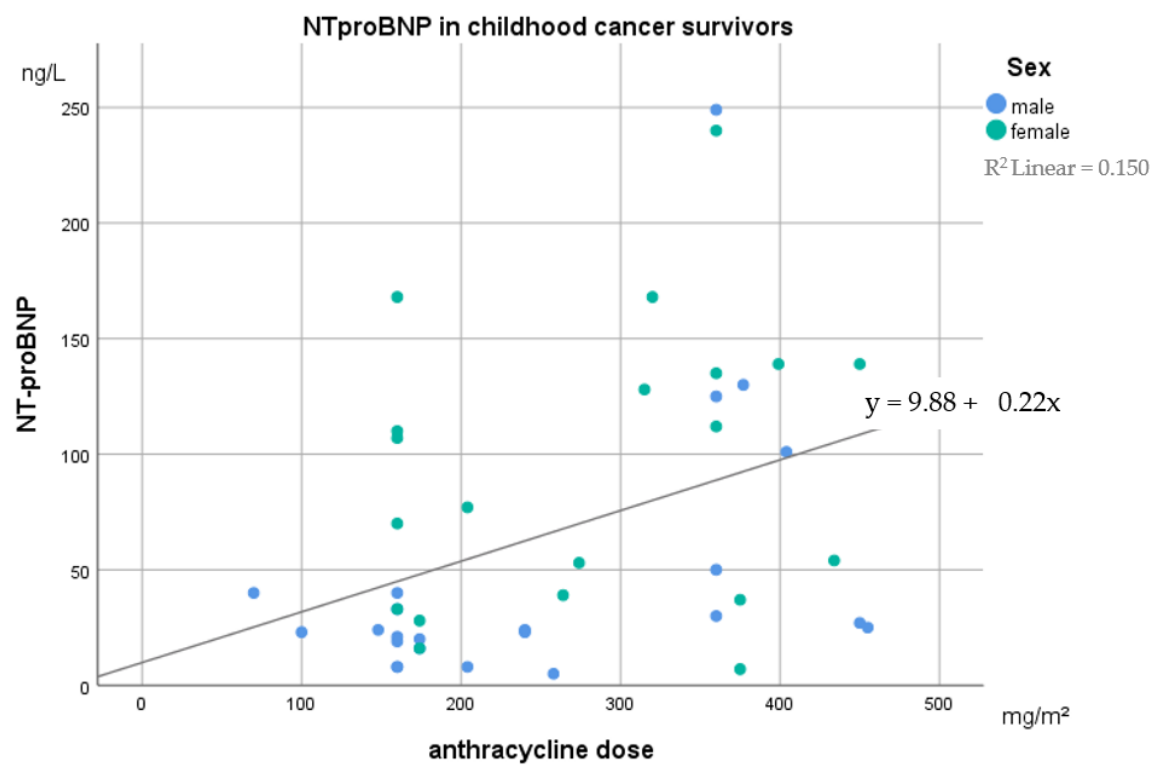

Figure 2. Correlation of N-terminal pro-brain natriuretic peptide (NTproBNP) and anthracycline dosage in childhood cancer survivors after around 10 years.

The group with moderate and high anthracyclines did significantly differ in NTproBNP values $(42.7 \pm 42.5 \mathrm{ng} / \mathrm{L}$ vs. $94.91 \pm 70.9 \mathrm{ng} / \mathrm{L}, p=0.005)$ and this holds true after correction for sex, age, height and weight differences $(47.6 \pm 13.5 \mathrm{ng} / \mathrm{L}$ vs. $90.2 \pm 13.2 \mathrm{ng} / \mathrm{L}$; $p=0.042$ ).

Adjusting for the same covariates, there were no differences in RRsys ( $p=0.237)$, zRRsys $(p=0.579)$, PWV $(p=0.542)$ or RRdia $(p=0.450)$ between patients with normal vs. abnormal NTproBNP values.

\section{Discussion}

This study showed that despite the fact that all CCS were asymptomatic, a substantial number of patients had a diminished exercise capacity and an elevated NT-proBNP, which correlated with anthracycline dosage. A vascular component (cIMT, central and peripheral blood pressure) of anthracycline toxicity or a continuous cardiotoxic process (cTNT) could not be detected.

The current state of literature does not allow a clear statement about the risk of thickened cIMT in CCS. In our cohort, at a mean time of 10 years after cancer diagnosis, cIMT values do not differ between CCS and healthy controls. This is in accordance with some recently published studies [29-31], but at the same time contradicts the results of others $[6,32,33]$.

$\mathrm{Li}$ et al. [33] registered increased cIMT values in anthracycline-treated CCS without radiation after an extended follow-up period of approximately 15 years after therapy completion. In long-term survivors of ALL [29,30] or Hodgkin's Lymphoma [31], no cIMT differences were found comparing patients to healthy controls. Even in patients with high blood pressure, no increased cIMT values were detected [29]. Ociepa et al. concluded that their studied group might be too young and that time since therapy is, with a median of 5.7 years, too short to see damaged arterial walls [29]. Our patients are on average 9 years older, but still show no abnormalities in cIMT. Therefore, either the period is still too short or the known increased risk for these patients is not reflected in increased cIMT values. 
The influence of previous radiation therapy is also questionable. For Example, Meeske et al [32] found increased cIMT values in CCS treated with neck irradiation, Zaletel et al. [31] did not. In addition, Sadurska et al. [6] reported increased cIMT in CCS regardless of whether the patients had radiation or not. In contrast to that, Boruwer et al. [34] found no increased cIMT in their large sample of CSS, but the values were significantly increased in the subgroup of CSS with radiotherapy.

The heterogeneity of the study results could be due to the heterogeneity of the examined patient groups (e.g. types of cancer, composition of the sample, mean time from cancer diagnosis), the small number of cases or the differences in the study protocol. On the other hand, the type of treatment (including the dosage of chemotherapy as well as the level and location of radiotherapy) could also have a decisive influence, which was not sufficiently taken into account in every study. For a final assessment, a study with a large number of cases and a cohort of older patients is necessary, which allows comparisons of homogenous groups with the same diagnosis and similar therapy.

None of our patients had cTNT $>0.01$. This is in line with Mavinkurve-Groothuis et al. [35], who suspected that this parameter is not usable for detecting late onset cardiotoxicity in CSS. With NTproBNP, however, it is completely different. Abnormal values of NTproBNP were prevalent in $11.6 \%$ of CCS, respectively. Studies in the general population have shown that even slightly elevated NTproBNP values (in the upper normal range) are associated with an increased cardiovascular risk and risk of death [36]. In addition, Dixon et al. [37] showed that NTproBNP could be used to identify asymptomatic patients at risk for cardiac events before changes in echocardiography become apparent. At the same time, Mavinkurve-Groothuis et al. [35] suspected that NTproBNP values in asymptomatic patients with normal echocardiography findings could be useful as a predictor for heart failure. In line with our results, however Dixon et al. have shown that there is a close correlation between the received anthracycline dose and later NTproBNP values, which is why they and others called NTproBNP a marker of treatment-related cardiotoxicity $[35,37]$ The sensitivity of NTproBNP as a screening parameter for left ventricular dysfunction was classified as low [38]. Several sources questioned the informative value of this parameter due to poor association with echocardiography findings [37,38]. Especially since there is currently still disagreement about suitable cut-off values $[35,38]$.

On the other hand, numerous studies have already shown an association of anthracycline dose and NTproBNP [35], as well as between increased NTproBNP and cardiac dysfunction in CCS $[39,40]$. In order to determine the predictive power of NTproBNP values, long-term studies of patients with increased NTproBNP values and at the same time inconspicuous echocardiography are required.

As expected, not all patients $(14.6 \%$ had RER $<1.1)$ achieved maximal exhaustion on CPET (e.g., due to physical discomfort or also prosthesis) and were excluded for further subgroup analysis in this field. A total of $28.6 \%$ of the remaining CCS showed abnormal performance even years after treatment. It was also demonstrated that CCS with higher anthracycline doses generally performed worse than patients with moderate anthracycline doses-additional radiation had no further effect on exercise performance.

A limited performance of CCS has been shown in various studies [41-43]. Further, most studies showed a negative influence of anthracyclines on physical performance [42]. Christiansen et al. [42] showed that a decreased exercise capacity is associated with impaired LV diastolic function and higher anthracycline dose in long-term survivors of childhood ALL. A comparatively inactive lifestyle [44] in CCS could be responsible for the generally limited exercise capacity of these patients in the physical performance test. Fatigue, anxiety, pain and a lack of motivation are some reasons for the sedentary lifestyle [45]. Wherever possible, an active lifestyle should be promoted for all CCS because of the protective effects. However, there is still no consensus on all the mechanisms of cancer therapy with a negative impact on exercise capacity in CCS, and further studies are needed. 


\section{Conclusions}

Even in asymptomatic pediatric cancer survivors after anthracycline therapy, NTproBNP and exercise capacity should be screened to find subtle signs of heart failure. About 10 years after cancer diagnosis, CCS that received high doses of anthracyclines are at a greater risk of high NTproBNP values and reduced exercise capacity than patients with moderate dosage. Long-term observation of patients with high NTproBNP values is necessary to verify the importance of these parameters. Thus, it would be important as the next step to examine a cohort of CCS at about 20 and 30 years after cancer treatment.

Further, the patients' cIMT and troponin levels were normal. There are no differences between CCS and controls or between the subgroups with moderate and high anthracyclines in these parameters. Consequently, they do not seem to be adequate parameters for the early detection of an increased cardiovascular risk in CCS.

\section{Limitations}

Because most patients had multi-modal treatments (various types of chemotherapy agents or surgeries, radiation exposure, ... ) it is difficult to address all factors of different cancer and treatment types in order to get homogenous patient groups. For further research, it would help to include a higher number of patients to cluster even more homogenous groups and determine the impact of individual exposures. In addition, a further long-term observation of the study participants would be useful in order to assess the predictive power of preventive markers.

Supplementary Materials: The following are available online at https: / www.mdpi.com/article/ 10.3390/jcm11030628/s1, File S1: Clinical protocol for Childhood Cancer Survivors at the German Heart Centre Munich.

Author Contributions: B.R., I.S., J.M., A.H., P.E., R.O.-F. and J.W. contributed to the conception and design of this study. B.R., I.S., T.S., J.M., A.H., J.H., P.E., C.W., R.O.-F. and J.W. contributed to the acquisition, analysis and/or interpretation of data for the work. B.R. drafted the manuscript. All listed authors critically revised the manuscript, gave final approval and agree to be accountable for all aspects of work ensuring integrity and accuracy. All authors have read and agreed to the published version of the manuscript.

Funding: This research received no external funding.

Institutional Review Board Statement: Ethical review and approval were waived for this study due to the complete retrospective design of the study.

Informed Consent Statement: Informed consent was obtained from all subjects involved in the study.

Data Availability Statement: The data of this study are available from the corresponding author on reasonable request.

Acknowledgments: We thank the German Heart Center Munich and the Institute of Preventive Pediatrics (TUM) for the opportunity to conduct this study and for the continued support in this project.

Conflicts of Interest: The authors declare that there is no conflict of interest.

\section{References}

1. Erdmann, F.; Kaatsch, P.; Grabow, D.; Spix, C. German Childhood Cancer Registry—Annual Report 2019 (1980-2018); Institute of Medical Biostatistics, Epidemiology and Informatics (IMBEI) at the University Medical Center of the Johannes Gutenberg University Mainz. 2020. Available online: https:/ /www.kinderkrebsregister.de/typo3temp/secure_downloads/42507/0/1c597 6c2ab8af5b6b388149df7182582a4cd6a39/Buch_DKKR_Jahresbericht_2019_komplett.pdf (accessed on 1 December 2021).

2. Nottage, K.A.; Ness, K.K.; Li, C.; Srivastava, D.; Robison, L.L.; Hudson, M.M. Metabolic syndrome and cardiovascular risk among long-term survivors of acute lymphoblastic leukaemia-From the St. Jude Lifetime Cohort. Br. J. Haematol. 2014, 165, 364-374. [CrossRef] [PubMed]

3. Mertens, A.C.; Liu, Q.; Neglia, J.; Wasilewski, K.; Leisenring, W.; Armstrong, G.T.; Robison, L.L.; Yasui, Y. Cause-Specific Late Mortality Among 5-Year Survivors of Childhood Cancer: The Childhood Cancer Survivor Study. J. Natl. Cancer Inst. 2008, 100, 1368-1379. [CrossRef] [PubMed] 
4. $\quad$ Armstrong, G.T.; Liu, Q.; Yasui, Y.; Neglia, J.; Leisenring, W.; Robison, L.L.; Mertens, A.C. Late Mortality Among 5-Year Survivors of Childhood Cancer: A Summary from the Childhood Cancer Survivor Study. J. Clin. Oncol. 2009, 27, 2328-2338. [CrossRef] [PubMed]

5. Talvensaari, K.K.; Lanning, M.; Tapanainen, P.; Knip, M. Long-term survivors of childhood cancer have an increased risk of manifesting the metabolic syndrome. J. Clin. Endocrinol. Metab. 1996, 81, 3051-3055. [CrossRef] [PubMed]

6. Sadurska, E.; Brodzisz, A.; Zaucha-Prażmo, A.; Kowalczyk, J. The Estimation of Intima-Media Thickness and Cardiovascular Risk Factors in Young Survivors of Childhood Cancer. J. Pediatr. Hematol. 2016, 38, 549-554. [CrossRef]

7. Wolf, C.M.; Reiner, B.; Kühn, A.; Hager, A.; Müller, J.; Meierhofer, C.; Oberhoffer, R.; Ewert, P.; Schmid, I.; Weil, J. Subclinical Cardiac Dysfunction in Childhood Cancer Survivors on 10-Years Follow-Up Correlates with Cumulative Anthracycline Dose and Is Best Detected by Cardiopulmonary Exercise Testing, Circulating Serum Biomarker, Speckle Tracking Echocardiography, and Tissue Doppler Imaging. Front. Pediatr. 2020, 8, 123. [CrossRef]

8. $\quad$ Dengel, D.R.; Kelly, A.S.; Zhang, L.; Hodges, J.S.; Baker, K.S.; Steinberger, J. Signs of early sub-clinical atherosclerosis in childhood cancer survivors. Pediatr. Blood Cancer 2013, 61, 532-537. [CrossRef]

9. Armenian, S.H.; Armstrong, G.T.; Aune, G.; Chow, E.J.; Ehrhardt, M.; Ky, B.; Moslehi, J.; Mulrooney, D.A.; Nathan, P.C.; Ryan, T.D.; et al. Cardiovascular Disease in Survivors of Childhood Cancer: Insights into Epidemiology, Pathophysiology, and Prevention. J. Clin. Oncol. 2018, 36, 2135-2144. [CrossRef]

10. Shepard, C.W.; Steinberger, J. Premature Atherosclerotic Cardiovascular Disease in Childhood Cancer Survivors. Prog. Pediatr. Cardiol. 2015, 39, 59-66. [CrossRef]

11. Enos, W.F.; Holmes, R.H.; Beyer, J. Coronary disease among United States soldiers killed in action in Korea; preliminary report. J. Am. Med. Assoc. 1953, 152, 1090-1093. [CrossRef]

12. Daniels, S.R. Cardiovascular disease risk factors and atherosclerosis in children and adolescents. Curr. Atheroscler. Rep. 2001, 3 , 479-485. [CrossRef] [PubMed]

13. Reiner, B.; Oberhoffer, R.; Häcker, A.-L.; Ewert, P.; Müller, J. Carotid Intima-Media Thickness in Children and Adolescents with Congenital Heart Disease. Can. J. Cardiol. 2018, 34, 1618-1623. [CrossRef] [PubMed]

14. de Groot, E.; Hovingh, G.K.; Wiegman, A.; Duriez, P.; Smit, A.J.; Fruchart, J.C.; Kastelein, J.J. Measurement of arterial wall thickness as a surrogate marker for atherosclerosis. Circulation 2004, 109, 33-38. [CrossRef] [PubMed]

15. Curren, V.; Dham, N.; Spurney, C. Diagnosis, Prevention, Treatment and Surveillance of Anthracycline-Induced Cardio-vascular Toxicity in Pediatric Cancer Survivors. Hearts 2021, 2, 45-60. [CrossRef]

16. Zhang, F.F.; Saltzman, E.; Must, A.; Parsons, S.K. Do Childhood Cancer Survivors Meet the Diet and Physical Activity Guidelines? A Review of Guidelines and Literature. Int. J. Child Health Nutr. 2012, 1, 44-58. [CrossRef]

17. Stolley, M.R.; Restrepo, J.; Sharp, L. Diet and Physical Activity in Childhood Cancer Survivors: A Review of the Literature. Ann. Behav. Med. 2010, 39, 232-249. [CrossRef]

18. Antwi, G.O.; Jayawardene, W.; Lohrmann, D.K.; Mueller, E.L. Physical activity and fitness among pediatric cancer survivors: A meta-analysis of observational studies. Support. Care Cancer 2019, 27, 3183-3194. [CrossRef]

19. McNeely, M.L.; Campbell, K.L.; Rowe, B.H.; Klassen, T.P.; Mackey, J.R.; Courneya, K.S. Effects of exercise on breast cancer patients and survivors: A systematic review and meta-analysis. Can. Med. Assoc. J. 2006, 175, 34-41. [CrossRef]

20. Schmid, D.; Leitzmann, M.F. Association between physical activity and mortality among breast cancer and colorectal cancer survivors: A systematic review and meta-analysis. Ann. Oncol. 2014, 25, 1293-1311. [CrossRef]

21. Albouaini, K.; Egred, M.; Alahmar, A.; Wright, D.J. Cardiopulmonary exercise testing and its application. Postgrad. Med. J. 2007, 83, 675-682. [CrossRef]

22. Liao, X.; Norata, G.D.; Polak, J.F.; Stehouwer, C.D.; Catapano, A.; Rundek, T.; Ezhov, M.; Sander, D.; Thompson, S.G.; Lorenz, M.W.; et al. Normative values for carotid intima media thickness and its progression: Are they transferrable outside of their cohort of origin? Eur. J. Prev. Cardiol. 2016, 23, 1165-1173. [CrossRef]

23. Reiner, B.; Oberhoffer, R.; Häcker, A.L.; Ewert, P.; Müller, J. Is Carotid Intima-Media Thickness Increased in Adults with Congenital Heart Disease? J. Am. Heart Assoc. 2020, 9, e013536. [CrossRef]

24. Dalla Pozza, R.; Ehringer-Schetitska, D.; Fritsch, P.; Jokinen, E.; Petropoulos, A.; Oberhoffer, R. Intima media thickness measurement in children: A statement from the Association for European Paediatric Cardiology (AEPC) Working Group on Cardiovascular Prevention endorsed by the Association for European Paediatric Cardiology. Atherosclerosis 2015, 238, 380-387. [CrossRef]

25. Gibbons, R.J.; Balady, G.J.; Bricker, J.T.; Chaitman, B.R.; Fletcher, G.F.; Froelicher, V.F.; Mark, D.B.; McCallister, B.D.; Mooss, A.N.; O'Reilly, M.G.; et al. ACC/AHA 2002 guideline update for exercise testing: Summary article. A report of the American College of Cardiolo-gy/American Heart Association Task Force on Practice Guidelines (Committee to Update the 1997 Exercise Testing Guidelines). J. Am. Coll. Cardiol. 2002, 40, 1531-1540. [CrossRef]

26. Müller, J.; Hess, J.; Hager, A. Sense of coherence, rather than exercise capacity, is the stronger predictor to obtain health-related quality of life in adults with congenital heart disease. Eur. J. Prev. Cardiol. 2014, 21, 949-955. [CrossRef] [PubMed]

27. Cooper, D.M.; Weiler-Ravell, D. Gas exchange response to exercise in children. Am. Rev. Respir. Dis. 1984, 129, S47-S48. [CrossRef] [PubMed]

28. Gläser, S.; Ittermann, T.; Schäper, C.; Obst, A.; Dörr, M.; Spielhagen, T.; Felix, S.B.; Völzke, H.; Bollmann, T.; Opitz, C.F.; et al. The Study of Health in Pomerania (SHIP) reference values for cardiopulmonary exercise testing. Pneumologie 2013, 67, 58-63. 
29. Ociepa, T.; Posio, W.; Sawicki, M.; Urasiński, T. CIMT does not identify early vascular changes in childhood acute lympho-blastic leukemia survivors. Adv. Clin. Exp. Med. 2020, 29, 243-249. [CrossRef] [PubMed]

30. Giordano, P.; Muggeo, P.; Delvecchio, M.; Carbonara, S.; Romano, A.; Altomare, M.; Ricci, G.; Valente, F.; Zito, A.; Scicchitano, P.; et al. Endothelial dysfunction and cardiovascular risk factors in childhood acute lympho-blastic leukemia survivors. Int. J. Cardiol. 2017, 228, 621-627. [CrossRef]

31. Zaletel, L.Z.; Popit, M.; Zaletel, M. Is Carotid Stiffness a Possible Surrogate for Stroke in Long-term Survivors of Childhood Cancer after Neck Radiotherapy? Radiol. Oncol. 2018, 52, 136-142. [CrossRef]

32. Meeske, K.A.; Siegel, S.E.; Gilsanz, V.; Bernstein, L.; Ms, M.B.N.; Sposto, R.; Weaver, F.A.; Lavey, R.S.; Mack, M.W.J.; Nelson, M.D Premature carotid artery disease in pediatric cancer survivors treated with neck irradiation. Pediatr. Blood Cancer 2009, 53, 615-621. [CrossRef] [PubMed]

33. Li, V.W.-Y.; Liu, A.P.-Y.; Ho, K.K.-H.; Yau, J.P.-W.; Cheuk, D.K.-L.; Cheung, Y.-F. Resting and exercise arterial dysfunction in anthracycline-treated adult survivors of childhood cancers. Cardio-Oncol. 2018, 4, 9. [CrossRef] [PubMed]

34. Brouwer, C.A.; Postma, A.; Hooimeijer, H.L.H.; Smit, A.J.; Vonk, J.M.; van Roon, A.M.; Berg, M.P.V.D.; Dolsma, W.V.; Lefrandt, J.D.; Bink-Boelkens, M.T.; et al. Endothelial Damage in Long-Term Survivors of Childhood Cancer. J. Clin. Oncol. 2013, 31, $3906-3913$. [CrossRef] [PubMed]

35. Mavinkurve-Groothuis, A.M.; Groot-Loonen, J.; Bellersen, L.; Msc, M.S.P.; Feuth, T.; Bökkerink, J.P.; Hoogerbrugge, P.M.; Kapusta, L. Abnormal NT-pro-BNP levels in asymptomatic long-term survivors of childhood cancer treated with anthracyclines. Pediatr. Blood Cancer 2009, 52, 631-636. [CrossRef]

36. Wang, T.J.; Larson, M.; Levy, D.; Benjamin, E.; Leip, E.P.; Omland, T.; Wolf, P.A.; Vasan, R.S. Plasma Natriuretic Peptide Levels and the Risk of Cardiovascular Events and Death. N. Engl. J. Med. 2004, 350, 655-663. [CrossRef]

37. Dixon, S.B.; Howell, C.R.; Lu, L.; Plana, J.C.; Joshi, V.M.; Luepker, R.V.; Durand, J.B.; Ky, B.; Lenihan, D.J.; Jefferies, J.L.; et al. Cardiac biomarkers and association with subsequent cardiomyopathy and mortality among adult survivors of childhood cancer: A report from the St. Jude Lifetime Cohort. Cancer 2021, 127, 458-466. [CrossRef]

38. Leerink, J.M.; Verkleij, S.J.; Feijen, E.A.M.; Mavinkurve-Groothuis, A.M.C.; Pourier, M.S.; Ylänen, K.; Tissing, W.J.E.; Louwerens, M.; Heuvel, M.M.V.D.; Broeder, E.V.D.-D.; et al. Biomarkers to diagnose ventricular dysfunction in childhood cancer survivors: A systematic review. Heart 2018, 105, 210-216. [CrossRef]

39. Aggarwal, S.; Pettersen, M.D.; Bhambhani, K.; Gurczynski, J.; Thomas, R.; L'Ecuyer, T. B-type natriuretic peptide as a marker for cardiac dysfunction in anthracycline-treated children. Pediatr. Blood Cancer 2007, 49, 812-816. [CrossRef]

40. Germanakis, I.; Kalmanti, M.; Parthenakis, F.; Nikitovic, D.; Stiakaki, E.; Patrianakos, A.; Vardas, P.E. Correlation of plasma $\mathrm{N}$-terminal pro-brain natriuretic peptide levels with left ventricle mass in children treated with anthracyclines. Int. J. Cardiol. 2006, 108, 212-215. [CrossRef]

41. Miller, A.M.; Lopez-Mitnik, G.; Somarriba, G.; Lipsitz, S.R.; Hinkle, A.S.; Constine, L.S.; Lipshultz, S.E.; Miller, T.L. Exercise capacity in long-term survivors of pediatric cancer: An analysis from the Cardiac Risk Factors in Childhood Cancer Survivors Study. Pediatric Blood Cancer 2013, 60, 663-668. [CrossRef]

42. Christiansen, J.R.; Kanellopoulos, A.; Lund, M.B.; Massey, R.; Dalen, H.; Kiserud, C.E.; Ruud, E.; Aakhus, S. Impaired exercise capacity and left ventricular function in long-term adult survivors of childhood acute lymphoblastic leukemia. Pediatric Blood Cancer 2015, 62, 1437-1443. [CrossRef] [PubMed]

43. Myrdal, O.H.; Kanellopoulos, A.; Christensen, J.R.; Ruud, E.; Edvardsen, E.; Kongerud, J.; Sikkeland, L.I.; Lund, M.B. Risk factors for impaired pulmonary function and cardiorespiratory fitness in very long-term adult survivors of childhood acute lymphoblastic leukemia after treatment with chemotherapy only. Acta Oncol. 2018, 57, 658-664. [CrossRef] [PubMed]

44. Florin, T.; Fryer, G.E.; Miyoshi, T.; Weitzman, M.; Mertens, A.C.; Hudson, M.M.; Sklar, C.A.; Emmons, K.; Hinkle, A.; Whitton, J.; et al. Physical Inactivity in Adult Survivors of Childhood Acute Lymphoblastic Leukemia: A Report from the Childhood Cancer Survivor Study. Cancer Epidemiol. Biomark. Prev. 2007, 16, 1356-1363. [CrossRef] [PubMed]

45. Cox, C.L.; Montgomery, M.; Oeffinger, K.C.; Leisenring, W.; Zeltzer, L.; Whitton, J.A.; Mertens, A.C.; Hudson, M.M.; Robison, L.L. Promoting physical activity in childhood cancer survivors: Results from the Childhood Cancer Survivor Study. Cancer 2009, 115, 642-654. [CrossRef] 